\title{
A study in vitro of the sensitivity to antibiotics of Bacteroides fragilis
}

\author{
H. R. INGHAM, J. B. SElKON, A. A. CODD, AND J. H. HALE \\ From the Regional Public Health Laboratory, General Hospital, \\ Newcastle upon Tyne
}

SYNOPSIS During a two-year period of observation Bacteroides species were isolated from specimens? of pus and vaginal swabs from 115 patients in this hospital. Thirty-five representative strains proved ${ }_{-}$ on examination to be Bacteroides fragilis.

Minimal inhibitory and minimal bactericidal concentrations of six antibiotics for these strains were determined. All strains were resistant to streptomycin, neomycin, and polymyxin, slightly sensitiveo to penicillin and ampicillin, and fully sensitive to tetracycline, chloramphenicol, erythromycin, and ${ }_{-}$ lincomycin. The minimum bactericidal concentrations of chloramphenicol, erythromycin, and $\mathrm{c}$ lincomycin were two to four times the minimal inhibitory concentrations. Tetracycline failed to exert any consistent bactericidal effect.

The treatment of patients with infections caused by $B$. fragilis is discussed in the light of the. findings in vitro.

The name Bacteroides or Fusiformis is used to describe a group of Gram-negative bacilli which are non-sporing obligate anaerobes (Wilson and Miles, 1964; Cowan and Steel, 1965). Their natural habitat is the large intestine, mouth, and vagina. On occasion these organisms may be pathogenic and the isolation of Bacteroides species from suppuration in man has been well documented.

Gillespie and Guy (1956) reviewed the literature on the subject and reported the sensitivity to antibiotics of strains isolated from 111 specimens of abdominal pus. These authors did not identify these strains at the species level but reported that most of them were resistant to penicillin, streptomycin, neomycin, and polymyxin, fully sensitive to chloramphenicol and tetracycline, and moderately or fully sensitive to erythromycin. Garrod (1955) investigated the sensitivity of four species of Bacteroides to various antibiotics and found that all were resistant to streptomycin but sensitive to chloramphenicol and tetracycline. Three of the species were sensitive to penicillin but only $B$. melaninogenicum was fully sensitive to erythromycin.

During the last two years in this laboratory Bacteroides species have been isolated from 115 patients, who in many instances had severe infec- tions, including four cerebral abscesses. Using the paper disc sensitivity method 112 of these strains $\Rightarrow$ were found to be sensitive to tetracycline, chloram-응 phenicol, and erythromycin, and all were resistant topenicillin, streptomycin, neomycin, and polymyxin In view of the frequency with which these penicillin resistant strains were encountered in serious sup purative lesions and the chemotherapeutic problemso which they posed, 35 representative strains were identified and their sensitivity in vitro to antibioticso was examined in detail. This communication records the results of these investigations.

MATERIALS AND METHODS

STRAINS The 115 strains of Bacteroides were isolated from the same number of patients on routine anaerobico culture on blood agar of swabs or purulent materiafw from sites other than the mouth or respiratory tract. Alb plates were incubated at $37^{\circ} \mathrm{C}$ for at least 48 hours in an atmosphere of pure hydrogen in a Mackintosh and

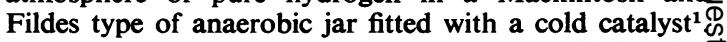
Colonies of Bacteroides were usually just visible after 24 hours' incubation but in some instances growth was not visible until 48 hours. Of the 115 strains, three were on colonial morphology different from the remainder and were penicillin-sensitive. These were identified as $B \bar{Q}$

${ }^{1}$ Baird and Tatlock (London) 
melaninogenicum (one strain) and $B$. necrophorus (two strains). The 35 strains examined in this study were chosen at random from the remaining 112 penicillinresistant strains. They were isolated from the sites shown in Table I.

\section{TABLE I} SOURCE OF STRAINS OF $B$. fragilis

\begin{tabular}{ll} 
Source & No. of Strains \\
\hline Vagina & 10 \\
Pus from peritoneal cavity & 4 \\
Appendix or post-appendicectomy wound infection & 5 \\
Wound infection after abdomino-perineal excision & 2 \\
of rectum & 7 \\
Abdominal wound infection & 1 \\
Ileal bladder & 2 \\
Cerebral abscess & 1 \\
Scrotal abscess & 1 \\
Wound infection after nephro-ureterectomy & 1 \\
Bartholin's abscess & 1 \\
Pus from tubo-ovarian abscess &
\end{tabular}

Type cultures of $B$. fragilis (NCTC 9343) and $B$. necrophorus (NCTC 7155) were examined as controls.

BIOCHEMICAL TESTS The biochemical tests utilized in the identification of these organisms were as detailed by Cowan and Steel (1965). One per cent sugars in peptone water were inoculated with a drop of an overnight culture in Robertson's cooked meat medium and incubated anaerobically at $37^{\circ} \mathrm{C}$. This technique has been shown to give the same results as those obtained using as the inoculum a loopful of growth from a blood agar plate, but has the advantage of usually allowing the results to be read after 48 hours' incubation instead of after four to six days.

Filter paper strips soaked in lead acetate were suspended over peptone water cultures to detect the production of $\mathrm{H}_{2} \mathrm{~S}$. The production of indole was detected by means of Kovak's reagent. Catalase production was detected by a modification of the technique described by Thomas (1963). A small quantity of growth was removed from a blood agar plate with a glass slide and suspended in a drop of 20 vol $\%$ hydrogen peroxide.

ANTIBIOTICS SENSITIVITY TESTS Doubling dilutions of antibiotics in concentrations shown in Table II were incorporated in blood agar plates which were prepared on the day before the test and stored at $+4^{\circ} \mathrm{C}$ overnight. A phage typing apparatus was used to inoculate the plates with suspension of the organisms in broth. The suspension was prepared by emulsifying colonies from a 48-hour blood agar culture in $2 \mathrm{ml}$ of broth so as to produce a faint turbidity, and then making up the volume to $10 \mathrm{ml}$. A suspension prepared in this manner contained approximately $10^{5}$ organisms per $\mathrm{ml}$. The Oxford Staphylococcus at a concentration of $10^{5} / \mathrm{ml}$ was used as the control. All plates were incubated anaerobically at $37^{\circ} \mathrm{C}$ for 48 hours. The minimum inhibitory concentration (MIC) was defined as the lowest concentration producing a marked decrease in colony size or allowing the growth to normal size of not more than 19 colonies. All plates on which growth was inhibited or absent were replica plated (Lederberg and Lederberg, 1952) with velvet pads on to antibiotic-free blood agar plates. After these plates had been incubated anaerobically for 48 hours, the bactericidal endpoints (MBC) were read, using as the definition of significant growth, the presence of 20 or more colonies.

DEVELOPMENT OF RESISTANCE Three of the 35 strains were serially passaged on ditch plates containing erythromycin or lincomycin and tested for the development of resistance.

\section{RESULTS}

The cultural characteristics and biochemical reactions of $B$. fragilis strain NCTC 9343 were as follows. On anaerobic culture on blood agar plates very small colonies were seen after 24 hours' incubation. After 48 hours' incubation the colonies measured from 0.5 to $1.0 \mathrm{~mm}$ in diameter, were greyish white with an unbroken edge and a smooth moist surface and were non-haemolytic. The strain was strongly catalase positive and produced $\mathrm{H}_{2} \mathrm{~S}$. Acid but not gas was produced from glucose, maltose, sucrose, and lactose, but not from mannitol. Indole was not produced.

The cultural characteristics of the 35 strains of Bacteroides examined in this study were indistinguishable from those exhibited by the type culture. The biochemical reactions of 25 strains were identical with those of the type strain. Of the remaining 10 strains, four produced indole, three produced indole and failed to ferment maltose, and four failed to ferment maltose. Four strains representative of the 35 included in this study were examined by Dr S. P. Lapage (Curator of the National Collection of Type Cultures, Colindale), who considered that these were strains of $B$. fragilis.

The minimal inhibitory and minimal bactericidal concentrations of the six antibiotics studied for the strains of $B$. fragilis are shown in Table II. Because of technical difficulties some of the strains were not tested against all six antibiotics. The MICs and MBCs of the different antibiotics follow a normal distribution and have a narrow range. The mean MICs of tetracycline, erythromycin, lincomycin, and chloramphenicol for these strains of $B$. fragilis were either the same as, or less than, that for the Oxford Staphylococcus. The MICs of penicillin and ampicillin for $B$. fragilis were more than 50 times those for the Oxford Staphylococcus.

A comparison of the minimal inhibitory and minimal bactericidal concentrations of these six antibiotics shows that only ampicillin and penicillin were bactericidal at, or very near to, their minimal inhibitory concentration. Chloramphenicol, lincomycin, and erythromycin were bactericidal at about 
TABLE II

\begin{tabular}{|c|c|c|c|c|}
\hline Antibiotic & $\begin{array}{l}\text { Concentration } \\
(\mu g / m l)\end{array}$ & $\begin{array}{l}\text { TIVITY OF B. fragilis To } \\
\text { Minimal Inhibitory } \\
\text { Concentration (no. of strains) }\end{array}$ & $\begin{array}{l}\text { A SERIES OF ANTIBIOTICS } \\
\text { Minimal Bactericidal } \\
\text { Concentration (no. of strains) }\end{array}$ & $\begin{array}{l}\text { Minimal Inhibitory } \\
\text { Concentration for the Oxford } \\
\text { Staphylococcus }(\mu \mathrm{g} / \mathrm{ml})\end{array}$ \\
\hline Penicillin & $\begin{array}{c}25 \\
12 \cdot 5 \\
6 \cdot 25 \\
3 \cdot 1 \\
\text { Total }\end{array}$ & $\begin{array}{r}-8 \\
9 \\
4 \\
21\end{array}$ & $\begin{array}{r}1 \\
11 \\
8 \\
1 \\
21\end{array}$ & 0.04 \\
\hline Ampicillin & $\begin{array}{c}16 \cdot 5 \\
8 \cdot 25 \\
4 \cdot 1 \\
2 \cdot 05 \\
\text { Total }\end{array}$ & $\begin{array}{r}1 \\
5 \\
11 \\
2 \\
19\end{array}$ & $\begin{array}{r}2 \\
7 \\
10 \\
19\end{array}$ & 0.06 \\
\hline Erythromycin & $\begin{array}{c}0.6 \\
0.3 \\
0.15 \\
0.07 \\
0.035 \\
\text { Total }\end{array}$ & $\begin{array}{r}-3 \\
12 \\
6 \\
5 \\
26\end{array}$ & $\begin{array}{r}11 \\
10 \\
4 \\
1 \\
26\end{array}$ & 0.15 \\
\hline Lincomycin & 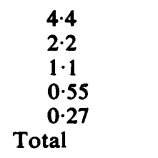 & $\begin{array}{r}-7 \\
7 \\
11 \\
3 \\
24\end{array}$ & $\begin{array}{r}3 \\
7 \\
11 \\
3 \\
24\end{array}$ & 0.26 \\
\hline Chloramphenicol & $\begin{array}{r}35.5 \\
17.7 \\
8.8 \\
4.4 \\
2.2 \\
\text { Total }\end{array}$ & $\begin{array}{r}- \\
3 \\
25 \\
3 \\
31\end{array}$ & $\begin{array}{r}1 \\
6 \\
23 \\
1 \\
31\end{array}$ & $4 \cdot 4$ \\
\hline Tetracycline & $\begin{array}{c}>6.6 \\
6.6 \\
3.3 \\
1.65 \\
0.82 \\
0.41 \\
\text { Total }\end{array}$ & $\begin{array}{l}= \\
= \\
\overline{6} \\
11 \\
17\end{array}$ & $\begin{array}{r}3 \\
4 \\
4 \\
6 \\
- \\
17\end{array}$ & 0.8 \\
\hline
\end{tabular}

two to four times their minimal inhibitory concentrations and tetracycline was irregularly bactericidal at eight times or greater than its minimal inhibitory concentrations.

Of the three strains of $B$. fragilis passaged every two days on ditch-plates containing erythromycin, at the fifteenth passage the sensitivity of one strain was unaltered at $0.3 \mu \mathrm{g} / \mathrm{ml}$ and those of the two other strains had increased approximately 16-fold to an MIC of $5 \mu \mathrm{g} / \mathrm{ml}$. The development of resistance by these two strains occurred in a stepwise manner at the third, seventh, and twelfth passages. None of the three strains showed any increase in resistance to lincomycin after the 15 passages on ditch-plates containing lincomycin.

\section{DISCUSSION}

The genus Bacteroides includes at least six species (Wilson and Miles, 1964), the biochemical reactions of four of them being listed by Cowan and Steef. (1965) in their 'Manual for the identification of medical bacteria'. It is therefore of interest that despite this variety of species, of the 115 strains of Bacteroides isolated in this laboratory, 112 wero $B$. fragilis. In previous papers reporting the isolation. of Bacteroides from human sources, other than from the mouth or respiratory tract, in which the species has been named, B. necrophorus (syn. B. funduliformis has been most frequently reported (Smith, McCallow and Blake, 1944; Ruys, 1947; Fisher and McKusicko 1953; McVay and Sprunt, 1952). Thus the present findings appear to be in disagreement with somळ previous reports. However, it is probable that this does not represent a genuine difference between the findings of different studies but merely reflects the different criteria used for identifying the specieso Considerable importance has often been attache $\bar{P}$ to the pleomorphism exhibited on primary isolation of $B$. necrophorus compared with other strains of 
Bacteroides, such as the production of long filaments often containing spherical swellings (Smith et al., 1944; Ruys, 1947). Such pleomorphism was also seen in some of the strains of $B$. fragilis on primary isolation in the current study and has also been reported in this species by Hoogendijk (1965). Pleomorphism alone must therefore be regarded as of limited taxonomic importance. Fisher and McKusick (1953) and McVay and Sprunt (1952), who reported the isolation of five and 15 strains respectively of $B$. necrophorus, did not report the use of biochemical tests in the identification of their strains. However, four of Fisher and McKusick's strains and all of McVay and Sprunt's 15 strains were resistant to $1 \mu \mathrm{g} / \mathrm{ml}$ or more of penicillin, a finding which is in contrast with that of Garrod (1955) who studied four strains of B. necrophorus (one from the National Collection of Type Cultures, two from the State Serum Institute, Copenhagen, and one from Dr J. M. Alston) and found that all were sensitive to $0 \cdot 12 \mu \mathrm{g} / \mathrm{ml}$ or less of penicillin. It is therefore possible that on present-day criteria most of Fisher and McKusick's and McVay and Sprunt's strains would be classified as $\boldsymbol{B}$. fragilis, since this is the only species of Bacteroides which is consistently resistant to this concentration of penicillin (Garrod, 1955). Hoogendijk (1965), reporting on the sensitivity to antibiotics of 25 strains of $B$. fragilis, stated that in his experience the majority of strains of Bacteroides isolated from human pathological material were resistant to benzylpenicillin. The report by Gillespie and Guy (1956) of the isolation of Bacteroides from 111 specimens of abdominal pus did not mention the species isolated. However, most of the strains were resistant to penicillin and have been referred to as B. fragilis by Wilson and Miles (1964). The results of this large series thus support the finding of the present study that the commonest Bacteroides that is isolated from human purulent material, other than from the mouth or respiratory tract, is $B$. fragilis.

Since the strains of $B$. fragilis examined in this study exhibited a uniform pattern of sensitivity to antibiotics, it is worthwhile to consider which antibiotic, would, on the basis of in vitro studies, be the most appropriate for the treatment of these infections. B. fragilis, though clearly relatively resistant to penicillin, is sensitive to the higher concentrations of penicillin and ampicillin which are attainable in the serum. It might be assumed that these antibiotics are appropriate for treatment if given in high dosage. However, the minimum bactericidal concentrations of ampicillin and penicillin for $B$. fragilis are at least 50 times greater than those for the Oxford Staphylococcus. These organisms are thus as resistant to ampicillin and penicillin as Streptococcus faecalis. Jawetz (1952) has shown that penicillin alone, even when given in very large doses, will usually not affect a cure in subacute bacterial endocarditis due to Streptococcus faecalis, an observation which has been substantiated by many authors. By analogy it is therefore unlikely that infections due to penicillinresistant Bacteroides would respond to treatment with either of these antibiotics. The failure of penicillin and streptomycin in the treatment of such infections has been well demonstrated by Gunn (1957).

Previous authors have recommended tetracycline for the treatment of infections due to penicillinresistant strains of Bacteroides (Gillespie and Guy, 1956; Garrod, 1955; Finegold and Hewitt, 1956; and Hoogendijk, 1965). This may be an appropriate antibiotic for the less serious types of infections due to these organisms, but when the infection is of a more serious nature, eg, cerebral abscess or extensive intraabdominal sepsis, treatment with an antibiotic capable of exerting a bactericidal action in concentrations attainable in the body would be preferable. Although chloramphenicol is bactericidal to $B$. fragilis it is not the antibiotic of first choice because of its potential toxicity.

The present results show that erythromycin and lincomycin are bactericidal to strains of $\boldsymbol{B}$. fragilis in concentrations two to four times their MICs, concentrations, which it has been shown, are exceeded in the blood after the oral or parenteral administration of suitable preparations (Griffith, Johnstone, and Smith, 1953; Griffith, 1959; Lopez-Belio, Takimura, Fornatto, and Holinger, 1957; Medina, Fiske, Hjelt-Harvey, Brown, and Prigot, 1963). Erythromycin is remarkably free from serious toxic effects, although reversible hepatic damage has occasionally been reported after the oral administration of erythromycin estolate for periods in excess of 14 days (Robinson, 1961; Kohlstaedt, 1961; Masel, 1962). No reports of hepatic injury have followed the administration of the intravenous preparation erythromycin lactobionate or of lincomycin.

The results of the present study thus suggest that on the basis of minimal bacteriostatic and minimal bactericidal concentrations, the most suitable antibiotic for treating infections due to $B$. fragilis is either erythromycin or lincomycin. In favour of lincomycin there is the finding that, in contrast to erythromycin, resistance did not develop during 15 passages in vitro. However, the choice between them remains a difficult one and will ultimately depend on clinical experience. In this respect it is worth mentioning that in this hospital erythromycin has been used successfully in the treatment of severe 
infections due to $B$. fragilis even though prolonged chemotherapy was required (to be published).

We are grateful to Dr S. P. Lapage, Curator, National Collection of Type Cultures, Colindale, for identifying the strains sent to him, and to Miss J.Dutton, F.I.M.L.T., who was responsible for the isolation of the majority of these strains.

\section{REFERENCES}

Cowan, S. T., and Steel, K. J. (1965). Manual for the Identification of Medical Bacteria. Cambridge University Press, London.

Finegold, S. M., and Hewitt, W. L. (1956). Antibiot. Ann. (1955-56), 794.

Fisher, A. M., and McKusick, V. A. (1953). Amer. J. med. Sci., 225, 253.

Garrod, L. P. (1955). Brit. med. J., 2, 1529.

Gillespie, W. A., and Guy, J. (1956). Lancet, 1, 1039.
Griffith, R. S., Johnston, D. M., and Smith, J. W. (1953). Antibiot. Ann. (1953-54), 496.

Griffith, R. S. (1959). Antibiot. Ann. (1958-59), 364

Gunn, A. A. (1957). Arch. Dis. Childh., 32, 523.

Hoogendijk, J. L. (1965). Antonie v. Leeuwenhoek, 31, 383.

Jatwez, E. (1952). Arch. intern Med., 90, 301.

Kohlstaedt, K. G. (1961). J. Amer. med. Ass., 178, 89.

Lederberg, J., and Lederberg, E. M. (1952). J. Bact., 63, 399.

Lopez-Belio, M., Takimura, Y., Fornatto, E. J., and Holinger, P. H. (1957). Antibiot. Ann. (1956-57), 152.

McVay, L. Y., Jr., and Sprunt, D. H. (1952). Ann. intern. Med., 36, 56.

Masel, M. A. (1962). Med. J. Aust., 1, 560.

Medina, A., Fiske, N., Hjelt-Harvey, I., Brown, C. D., and Prigot, A. (1963). Antimicrob. Agents and Chemother., 3, 189.

Robinson, M. M. (1961). J. Amer. med. Ass., 178, 89.

Ruys, A. C. (1947). J. Path. Bact., 59, 313.

Smith, W. E., McCall, R. E., and Blake, T. J. (1944). Ann. intern. $\overrightarrow{\mid}$ Med., 20, 920.

Thomas, M. (1963). Mth. Bull. Minist. Hlth Lab. Serv., 22, 124.

Wilson, G. S., and Miles, A. A. (1964). Topley and Wilson's principles $\frac{\widehat{O}}{0}$ of Bacteriology and Immunity, 5th ed., p. 614, and vol. 2, p. iv 2144. Arnold, London. 